УДК 332.142:316.346.32-053.9

\title{
РЕГИОНАЛЬНЫЙ АСПЕКТ БЕДНОСТИ ПОЖИЛЫХ ЛЮДЕЙ В РОССИИ
}

\author{
Фролова Елена Александровна 1 , \\ frolova_ea@mail.tsu.ru \\ Маланина Вероника Анатольевна², \\ milanskaya@mail.ru \\ Касати Фабио 2 , \\ fabio.casati@gmail.com \\ Шавлохова Анна Александровна², \\ ollyvost@tpu.ru \\ ${ }^{1}$ Национальный исследовательский Томский государственный университет, \\ Россия, 634050, г. Томск, пр. Ленина, 36 \\ ${ }^{2}$ Национальный исследовательский Томский политехнический университет, \\ Россия, 634050, г. Томск, пр. Ленина, 30
}

\begin{abstract}
Фролова Елена Александровна, доктор экономических наук, профессор кафедры экономики Национального исследовательского Томского государственного университета.
\end{abstract}

Маланина Вероника Анатольевна, кандидат экономических наук, доцент отделения социально-гуманитарных наук Национального исследовательского Томского политехнического университета.

Касати Фабио, Ph.D., ведущий научный сотрудник Международной научно-образовательной лаборатории технологий улучшения благополучия пожилых людей Национального исследовательского Томского политехнического университета.

Шавлохова Анна Александровна, инженер Организационного отдела Национального исследовательского Томского политехнического университета.

В мировой экономической науке и политике борьба с бедностью и неравенством продолжает быть актуальной, несмотря на десятилетия усилий по их преодолению. В отношении людей трудоспособного возраста и ниже трудоспособного усилия традиционно сосредоточены на обеспечении доступа к образованию и рабочим местам. Использование аналогичных инструментов в борьбе с бедностью среди пожилых людей может быть менее эффективным в силу меньшей предельной полезности образования и снижающихся возможностей доступа к высокооплачиваемым рабочим местам. Предполагается, что благосостояние старшего поколения гарантировано либо государством, либо самими пожилыми людьми, получающими отдачу от сделанных в течение жизненного пути инвестиций. Цель исследования - поиск институциональных и личностных факторов, действующих и формирующихся в течение всего жизненного курса и определяющих благосостояние пожилых людей. Тестировались такие факторы, как образование, стаж работы, количество членов домохозяйства, семейное положение, пол, территория проживания (город/деревня) и регион проживания. Методы: методы описательных статистик и корреляционный анализ на выборках Комплексного наблюдения условий жизни населения (КОУЖ-2018) для людей пенсионного возраста в России. Дополнительно для проверки результатов использованы данные Выборочного наблюдения доходов населения и участия в социальных программах (ВНДН-2017) и Европейского социального исследования (ESS-2018). Результаты: проведенные оценки корреляций между индикаторами социально-экономического статуса показали, что только количество членов домохозяйства в выборках ВНДН и ESS значимо и сильно положительно коррелирует с доходами в пожилом возрасте. Отсутствие работы негативно коррелирует с доходами горожан и доходами женщин. Оценки абсолютной и относительной бедности 
для федеральных округов различаются от 1 до $240 \%$. Субъективная бедность домохозяйств в России превышает $50 \%$.

Ключевые слова: Пожилые люди, бедность, субъективная бедность, доходы, занятость, домохозяйства, Федеральные округа.

\section{Введение}

Проблема бедности является ключевой для мирового сообщества, усилия которого вот уже много десятилетий сосредоточены на преодолении так называемой «крайней бедности» (extreme poverty) $[1,2]$. Однако крайняя нищета не характерна для стран Европы, включая Россию, и относительная бедность становится более корректным методом определения качества жизни старшего поколения [3-5]. Контекст, в котором формируются предпосылки для бедности пожилых людей, включает в себя дизайн и охват пенсионных систем, устойчивость и надежность инструментов инвестирования, наличие системы прожиточного минимума в стране и практика его индексации, уровень инфляции, степень доверия к власти со стороны граждан $[6,7]$.

Бедность среди трудоспособного населения России существенно выше бедности среди пожилых - в среднем 27 \% против 7,73\%. Понимание страновых, национальных, региональных условий формирования бедности, особенно в пожилом возрасте, когда набор инструментов ее преодоления существенно ограничен, позволяет принимать более специфичные меры по ее преодолению [8,9].

\section{Сравнительный анализ рисков и причин бедности для разных групп пожилых людей в РФ}

Для выявления причин бедности сравним профили бедных (официально имеющих статус малоимущих в базах данных социологических опросов) пожилых людей и тех, кто не относится к категории малоимущих. Статус человека как малоимущего может являться результатом множества одновременно действующих институциональных и личностных факторов. Профили бедных и небедных пожилых россиян совпадают: по гендеру (более $60 \%$ - женщины) и здоровью (порядка $14 \%$ - люди с инвалидностью), но заметно отличаются по территориальному принципу (материально благополучными являются в основном горожане); наличию и поиску работы (втрое больше бедных пожилых ищут работу в сравнении с небедными соотечественниками); помощи со стороны (28 \% небедных помогают дети, среди них же значительная доля - $27 \%$ респондентов - вообще не нуждается в помощи). Более материально благополучные пожилые чаще состоят в браке, но неочевидно, является ли это причиной, следствием относительного материального благополучия либо в принципе не связано с последним. Также среди небедных почти $21 \%$ получают заработную плату, что вчетверо больше, чем среди малоимущих [10]. Пренебрежимо малая доля респондентов в обеих категориях (порядка 1,7 \%) имеет доход от арендных платежей в пожилом возрасте (или, по крайней мере, готова поделиться такой информацией с интервьюерами).

С целью выявления потенциальных предикторов бедности среди пожилых был проведен корреляционный анализ некоторых социально-демографических характеристик и дохода на члена домохозяйства как для всей выборки пожилых людей КОУЖ2018, так и для отдельных групп населения. Типичными для тестирования подобной гипотезы являются гендерный и территориальный (город/деревня) принципы выделения подгрупп (табл. 1). 
Таблица 1. Таблица корреляций социально-демографических характеристик пожилых людей и их подушевого дохода (КОУЖ-2018)

Table 1. Table of correlations between socio-demographic characteristics and income per capita for older adults (CMLC-2018)

\begin{tabular}{|c|c|c|c|c|c|c|c|}
\hline $\begin{array}{l}\text { Подушевой } \\
\text { доход } \\
\text { Income p/c }\end{array}$ & $\begin{array}{c}\text { Коэффициент } \\
\text { корреляции } \\
\text { Correlation } \\
\text { coefficient }\end{array}$ & $\begin{array}{l}\text { Бедные } \\
\text { Poor } \\
\text { people }\end{array}$ & $\begin{array}{c}\text { Кол-во членов } \\
\text { Домохозяйства } \\
\text { people in } \\
\text { household }\end{array}$ & $\begin{array}{c}\text { Отсутствие } \\
\text { работы } \\
\text { Unemployed } \\
\text { people }\end{array}$ & $\begin{array}{c}\text { Кол-во лет } \\
\text { образования } \\
\text { Years of } \\
\text { education }\end{array}$ & $\begin{array}{c}\text { Стаж } \\
\text { Work } \\
\text { experi- } \\
\text { ence }\end{array}$ & $\begin{array}{c}\text { Прожива- } \\
\text { ние в сель- } \\
\text { ской мест- } \\
\text { ности } \\
\text { Rural men }\end{array}$ \\
\hline \multirow[t]{3}{*}{$\begin{array}{c}\text { пожилые } \\
\text { older adults }\end{array}$} & $\begin{array}{c}\text { Po Спирмена } \\
\text { Spearman's Rho }\end{array}$ &,$- 459^{* *}$ &,$- 122^{* * *}$ &,$- 314^{* *}$ &, $237^{* *}$ &, $138^{* *}$ &,$- 254^{* * *}$ \\
\hline & Sig. & 0,000 & 0,000 & 0,000 & 0,000 & 0,000 & 0,000 \\
\hline & $\mathrm{N}$ & 45802 & 45802 & 45802 & 45802 & 45802 & 45802 \\
\hline \multirow[t]{3}{*}{$\begin{array}{c}\begin{array}{c}\text { мужчины } \\
\text { (male) }\end{array} \\
\end{array}$} & $\begin{array}{c}\text { Ро Спирмена } \\
\text { Spearman's Rho }\end{array}$ &,$- 464^{* *}$ &,$- 130^{* *}$ &,$- 292^{* *}$ &, $262^{* * *}$ &, $122^{* *}$ &,$- 283^{* *}$ \\
\hline & Sig. & 0,000 & 0,000 & 0,000 & 0,000 & 0,000 & 0,000 \\
\hline & $\mathrm{N}$ & 16883 & 16883 & 16883 & 16883 & 16883 & 16883 \\
\hline \multirow[t]{3}{*}{$\begin{array}{c}\text { женщины } \\
\text { (female) }\end{array}$} & $\begin{array}{c}\text { Ро Спирмена } \\
\text { Spearman's Rho }\end{array}$ &,$- 456^{* *}$ &,$- 123^{* *}$ &,$- 337^{* *}$ &, $224^{* *}$ &, $145^{* *}$ &,$- 236^{* *}$ \\
\hline & Sig. & 0,000 & 0,000 & 0,000 & 0,000 & 0,000 & 0,000 \\
\hline & $\mathrm{N}$ & 28919 & 28919 & 28919 & 28919 & 28919 & 28919 \\
\hline \multirow[t]{3}{*}{ город (city) } & $\begin{array}{c}\text { Ро Спирмена } \\
\text { Spearman's Rho }\end{array}$ &,$- 385^{* *}$ &,$- 060^{* * *}$ &,$- 355^{* *}$ & $232^{* *}$ &, $097^{* *}$ & NA \\
\hline & Sig. & 0,000 & 0,000 & 0,000 & 0,000 & 0,000 & \\
\hline & $\mathrm{N}$ & 30274 & 30274 & 30274 & 30274 & 30274 & \\
\hline \multirow[t]{3}{*}{ село (rural) } & $\begin{array}{c}\text { Po Спирмена } \\
\text { Spearman's Rho }\end{array}$ &,$- 560^{* *}$ &,$- 248^{* *}$ &,$- 226^{* *}$ &, $145^{* *}$ &, $150^{* *}$ & NA \\
\hline & Sig. & 0,000 & 0,000 & 0,000 & 0,000 & 0,000 & \\
\hline & $\mathrm{N}$ & 15528 & 15528 & 15528 & 15528 & 15528 & \\
\hline
\end{tabular}

Предполагалось, что подушевой доход в пожилом возрасте должен сильно коррелировать с наличием официального статуса «малоимущего» гражданина, чего не наблюдается, в том числе и в разрезе макрорегионов. Во всех федеральных округах Российской Федерации корреляция подушевого дохода и статуса бедного колеблется в пределах от , $407 * *$ в Северо-Западном ФО до -,471** в Северо-Кавказском ФО, при среднем значении -,416** для страны в целом. Вклад в ситуацию вносит также разный прожиточный минимум пенсионеров в разных регионах и возможности местных властей манипулировать этой границей, занижая или не индексируя ее, тем самым сокращая количество официально зарегистрированных малоимущих граждан и демонстрируя видимость прогресса в борьбе с бедностью. Сам по себе факт слабой корреляции статуса малоимущего с доходами свидетельствует о неадекватности величин прожиточного минимума как точки отсчета в определении бедности. Вместе с тем корреляция между доходом и статусом оказывается сильной и значимой для сельского населения $(-, 560 * *)$, что позволяет выделить в России одну экстерриториальную (не связанную с административным делением) социальную группу пожилых людей - деревенских жителей, для которых место проживания ограничивает возможности получения доходов как в трудоспособном, так и тем более в пожилом возрасте.

Выборка пожилых людей, представленная в КОУЖ-2018, демонстрирует слабую отрицательную корреляцию с количеством лиц в составе домохозяйства, что в некоторой степени дает основания для понимания роли пожилых людей в домохозяйстве в качестве доноров. Однако, по данным Выборочного наблюдения доходов населения и участия в 
социальных программах (ВНДН-2017) [11] и Европейского социального исследования (ESS-2018) [12], ситуация диаметрально противоположна: корреляция дохода и количества лиц в домохозяйстве сильная и положительная (по ВНДН ,618**, по ESS ,723**). Тут уже пожилые люди выглядят скорее бенефициарами в рамках большой семьи, получая выгоду от присутствия в домохозяйстве партнеров и трудоспособных детей.

Отсутствие работы в пожилом возрасте также не может считаться фактором, сильно коррелирующим с доходом на выборке в целом. Анализ отдельных групп показал, что отсутствие работы сильнее коррелирует с доходом для жителей городов в сравнении с жителями села и для женщин в сравнении с мужчинами. Заметим, что для населения в трудоспособном возрасте в России доход значимо и сильно коррелирует со статусом малоимущего (-,755**), что еще раз подчеркивает, что прожиточный минимум пенсионера является в России неоправданно заниженным в сравнении с трудоспособным населением.

Актуальной универсальной рекомендацией для обеспечения благосостояния и высокого уровня жизни в любом возрасте является образование. Однако для текущих поколений пожилых людей этот фактор пока статистически слабо коррелирует с доходами в пожилом возрасте (,237** по России в целом). Постоянные корректировки пенсионной системы, пенсионной формулы, к сожалению, приводят к тому, что пожилые люди сейчас не получают значительной отдачи от стажа работы, корреляция которого с доходом еще слабее, чем с образованием $\left(, 138^{* *}\right)$. Соответственно, налицо дефлирующее и дезориентирующее влияние институциональных факторов на благосостояние пожилых людей в России.

\section{Рейтинг регионов РФ по критериям бедности}

Первым шагом для понимания региональных особенностей бедности в России являются выявление относительной доли бедных среди пожилых людей в каждом субъекте и построение рейтинга. В табл. 2 выборочно представлены данные по доле малоимущих (бедных) среди пожилого населения для регионов с самой высокой бедностью (выше 12 \%) и с самой низкой бедностью (ниже 2 \%). Медианным значением для субъектов Российской Федерации является 8,29 \% пожилых бедных (Ивановская область).

Абсолютная бедность среди пожилых людей в России теоретически должна отсутствовать в силу действующего законодательства, обязывающего компенсировать недостаточность доходов пенсионеров до соответствующего регионального прожиточного минимума. В базах данных социальных опросов тем не менее цифры далеки от нуля в силу специфики самого вопроса, который задают респондентам, - относительно среднего дохода на члена домохозяйства. Соответственно, при наличии иждивенцев средний подушевой доход таких респондентов падает ниже прожиточного минимума. Описательные статистики свидетельствуют о значительной доле бедных среди пожилых в национальных округах, краях и республиках - их большинство среди антилидеров рейтинга. Регионы с высокой долей бедных пожилых - совсем необязательно бедные сами по себе, среди антилидеров по бедности есть регионы как с критически низким (Чеченская Республика), так и с очень высоким (Ненецкий автономный округ) ВРП на душу населения. Тем не менее дотационные регионы «четвертой России», не имеющие развитого промышленного производства и научно-образовательного комплекса [13], с бедностью пожилых справляются хуже остальных. 
Таблища 2. Доля малоимущих (бедных) в составе пожилого населения в субъектах Российской Федерации (КОУЖ-2018)

Table 2. Share of low-income (poor) individuals among older adults in Russian regions (CMLC-2018)

\begin{tabular}{|l|c|}
\hline \multicolumn{1}{|c|}{ Субъект PФ/Region } & $\begin{array}{c}\text { Доля бедных пожилых, \% } \\
\text { Share of poor older adults }\end{array}$ \\
\hline Республика Тыва/Туva Republic & 26,26 \\
\hline Республика Дагестан/The Republic of Dagestan & 24,25 \\
\hline Кабардино-Балкарская Pecпублика/Kabardino-Balkar Republic & 23,86 \\
\hline Республика Алтай/Altai Republic & 22,81 \\
\hline Забайкальский край/Zabaykalsky Krai & 22,20 \\
\hline Псковская область/Pskov region & 21,07 \\
\hline Карачаево-Черкесская Pecпублика/Karachay-Cherkess Republic & 18,31 \\
\hline Курганская область/Kurgan region & 18,23 \\
\hline Еврейская автономная область/Jewish Autonomous Region & 18,06 \\
\hline Республика Бурятия/The Republic of Buryatia & 17,14 \\
\hline Красноярский край/Krasnoyarsk region & 16,17 \\
\hline Ненецкий автономный округ/Nenets Autonomous Okrug & 16,00 \\
\hline Чеченская Республика/Chechen Republic & 15,42 \\
\hline Пермский край/Реrm region & 13,99 \\
\hline Республика Саха/The Republic of Sakha & 13,33 \\
\hline Ульяновская область/Ulyanovsk region & 13,19 \\
\hline Амурская область/Amurskaya Oblast & 12,92 \\
\hline Вологодская область/Vologodskaya Oblast & 12,76 \\
\hline Республика Карелия/Republic of Karelia & 12,54 \\
\hline Республика Северная Oceтия-Aлания/Republic of North Ossetia-Alania & 12,34 \\
\hline Республика Коми/Komi Republic & 12,29 \\
\hline Калужская область/Kaluga region & 1,90 \\
\hline Чукотский автономный округ/Chukotka Autonomous District & 1,30 \\
\hline Город Москва/Моsсоw city & 1,18 \\
\hline Город Санкт-Петербург/Saint Petersburg city & 0,00 \\
\hline & \\
\hline
\end{tabular}

В рамках исследования был также построен рейтинг макрорегионов (федеральных округов) по всем видам бедности. Абсолютная бедность традиционно трактуется как доля респондентов среди пожилых людей, средние подушевые доходы которых ниже прожиточного регионального минимума [14-16]. Относительная бедность для целей данного исследования трактуется как доля респондентов среди пожилых людей, средние подушевые доходы которых ниже 60 \% от национальной медианы доходов. Задача данного индикатора - показать, насколько доходы исследуемой группы сопоставимы с медианными доходами социального окружения пожилых людей и насколько последние материально обеспечены и платежеспособны относительно всего населения в целом.

Субъективная бедность или бедность по расходам может быть оценена с помощью вопросов, касающихся оценки достаточности дохода для покрытия необходимых расходов [17-19]. Субъективная бедность по сути отражает личную оценку степени депривации, которая имплицитно привязана и к уровню дохода индивида или домохозяйства, который субъективно сопоставляется с расходами. В КОУЖ вопрос задается в рамках обследования домохозяйств и сформулирован следующим образом: «Принимая во внимание доходы всех членов домохозяйства, получается ли у Вашего домохозяйства "свести концы с концами", т. е. оплатить все необходимые ежедневные расходы?». Респонденты субъективно оценивают указанную способность по предложенной шкале от 1 (с большими затруднениями) до 6 (очень легко). Для целей данного исследования к числу 
субъективно бедных отнесены респонденты, «сводящие концы с концами» с «затруднениями» и «большими затруднениями» (2 и 1 по шкале опросника) $[12,14,20]$.

Таблища 3. Виды бедности по федеральным округам РФ (КОУЖ-2018) Table 3. Types of poverty, Federal districts breakdown (CMLC-2018)

\begin{tabular}{|l|c|c|c|}
\hline \multicolumn{1}{|c|}{$\begin{array}{c}\text { Федеральный округ } \\
\text { Region }\end{array}$} & $\begin{array}{c}\text { абсолютная бедность, \% } \\
\text { absolute poverty }\end{array}$ & $\begin{array}{c}\text { относительная бедность, \% } \\
\text { relative poverty }\end{array}$ & $\begin{array}{c}\text { субъективная бедность, \% } \\
\text { subjective poverty }\end{array}$ \\
\hline $\begin{array}{l}\text { Северо-Кавказский ФО } \\
\text { North Caucasian Federal } \\
\text { District }\end{array}$ & 16,02 & 14,13 & 63,7 \\
\hline $\begin{array}{l}\text { Дальневосточный ФО } \\
\text { Far Eastern Federal District }\end{array}$ & 10,91 & 5,13 & 60,6 \\
\hline $\begin{array}{l}\text { Сибирский ФO } \\
\text { Siberian Federal District }\end{array}$ & 10,84 & 7,82 & 62,6 \\
\hline $\begin{array}{l}\text { Уpaльский ФО } \\
\text { Ural Federal District }\end{array}$ & 8,65 & 4,93 & 56,3 \\
\hline $\begin{array}{l}\text { Приволжский ФО } \\
\text { Volga Federal District }\end{array}$ & 8,33 & 8,30 & 56,6 \\
\hline $\begin{array}{l}\text { Южный ФО } \\
\text { Southern Federal District }\end{array}$ & 7,88 & 5,67 & 62,2 \\
\hline $\begin{array}{l}\text { Юго-Западный ФО } \\
\text { South-Wеst Federal District }\end{array}$ & 7,80 & 3,27 & 57,1 \\
\hline $\begin{array}{l}\text { Центральный ФО } \\
\text { Сеntral Federal District }\end{array}$ & 4,57 & 3,42 & 59 \\
\hline
\end{tabular}

Как свидетельствуют описательные статистики в табл. 3, оценки монетарных типов бедности (абсолютной и относительной) не совпадают, но относительно близки в большинстве макрорегионов. Субъективная бедность домохозяйств, напомним, оценивается не по доходам, а по расходам, и преимущество такой оценки заключается в учете реального материального положения людей, их текущего соотношения доходов и расходов. Доходы домохозяйств и индивидов могут быть достаточно высокими в сравнении с региональным минимумом и национальной медианой и с формальной точки зрения не давать повода для беспокойства. При этом доходы все равно могут оказаться недостаточными для оплаты ежедневных покупок, коммунальных и медицинских услуг, если индивид или домохозяйство попадают в сложную жизненную ситуацию. Поэтому несмотря на высокую релевантность и учет материального положения в целом, а не только текущего дохода, оценка бедности по расходам связана с определенными трудностями в трактовке.

С институциональной точки зрения наше знание о субъективной бедности неоперационально, поскольку мы не получаем информации о причинах, длительности ситуации, в которой люди с трудом “сводят концы с концами”. Соответственно, как помочь субъективно бедным мы не знаем, поскольку за их оценками могут стоять как системные проблемы (например, недоступность бесплатной медицинской помощи и бесплатных лекарств и реабилитации в случае серьезного и длительного заболевания; недоступность гериатрических услуг для пожилых родственников), так и исключительно личностные разрушительные стратегии (алкоголизм, игромания).

\section{Дискуссия}

Исследование потенциальных предикторов бедности среди пожилых людей в России отчасти затруднено наличием разных стандартов отнесения к категории малоимущего населения в зависимости от региона проживания и величины прожиточного 
минимума, что сглаживает корреляционные связи дохода и бедности на национальном уровне. Данные по ответам респондентов, необходимым для оценки по субъективной бедности, присутствующие в опросниках КОУЖ и ВНДН, отсутствуют в базах данных результатов указанных опросов за большинство лет проведения исследований. Противоречивые результаты дает анализ различных баз данных: BНДН и ESS демонстрируют положительную корреляцию подушевого дохода с количеством членов домохозяйства, КОУЖ - отрицательную.

\section{Заключение}

Проведенный анализ больших данных по российским пожилым людям показал отсутствие сильных корреляций между институциональными факторами, потенциально способными формировать благосостояние человека в пожилом возрасте. На данном этапе для текущих поколений россиян старше пенсионного возраста отдачи от образования, стажа работы не наблюдается, что предсказуемо в условиях постоянных институциональных корректировок пенсионной системы. Разрыв между регионами по уровню абсолютной бедности среди пенсионеров составляет более 26 процентных пунктов, причем больше всего малоимущих в национальных республиках, краях и округах. Регионы с наибольшей долей бедных пожилых людей составляют кластеры, не совпадающие с границами федеральных округов, но концентрация таких территорий выше в Северо-Кавказском, Сибирском и Дальневосточном Федеральных округах.

Исследование выполнено за счет гранта Российского научного фонда (проект №19-18-00282).

\section{СПИСОК ЛИТЕРАТУРЫ}

1. Цели ООН в области устойчивого развития. URL: https://www.un.org/sustainabledevelopment/ru/ sustainable-development-goals/ (дата обращения 14.08.2020).

2. Доклад о неравенстве в мире - 2018: основные положения. URL: https://wir2018.wid.world/ files/download/wir2018-summary-russian.pdf (дата обращения 14.08.2020).

3. Sen A.K. Poor, relatively speaking // Oxford Economic Papers. - 1983. - V. 35. - № 2. - P. 153-169.

4. Sen A.K. From income inequality to economic inequality // Southern Economic Journal. - 1997. - V. 64. № 2. - P. 383-401.

5. Early J.F. Reassessing the facts about inequality, poverty, and redistribution // Policy Analysis. - 2018. № 839. - Washington: Cato Institute. URL: https://www.cato.org/publications/policy-analysis/reassessingfacts-about-inequality-poverty-redistribution (дата обращения 14.08.2020).

6. Капелюшников Р.И. Экономическое неравенство - вселенское зло? - М.: Изд. дом Высшей школы экономики, 2019. - 28 с.

7. Мареева С., Тихонова Н. Бедность и социальные неравенства в России в общественном сознании // Мир России. - 2016. - Т. 25. - № 2. - С. 37-67.

8. Is poverty measurable? // World Economic Forum. - 2019. URL: https://www.weforum.org/ agenda/2019/10/extreme-poverty-measurement-historian/ (дата обращения 14.08.2020).

9. The OECD approach to measure and monitor income poverty across countries // United nations economic commission for Europe conference of European statisticians. URL: https://www.unece.org/fileadmin/ DAM/stats/documents/ece/ces/ge.15/2013/WP_17_OECD_D_En.pdf (дата обращения 14.08.2020).

10. Комплексное наблюдение условий жизни населения - 2018 // Федеральная служба государственной статистики. URL: https://www.gks.ru/free_doc/new_site/KOUZ18/index.html (дата обращения 14.08.2020).

11. Выборочное наблюдение доходов населения и участия в социальных программах - 2017 // Федеральная служба государственной статистики. URL: https://www.gks.ru/free_doc/new_site/vndn2017/index.html (дата обращения 14.08.2020).

12. European Social Survey. URL: http://www.europeansocialsurvey.org/ (дата обращения 14.08.2020).

13. Зубаревич H. Четыре России и новая политическая реальность // ПОЛИТ.PУ. URL: https://polit.ru/article/2016/01/17/four_russians/ (дата обращения 14.08.2020). 
14. Величина прожиточного минимума // Федеральная служба государственной статистики. URL: https://rosstat.gov.ru/free_doc/new_site/population/urov/vpm/proj-min.html (дата обращения 14.08.2020).

15. Неравенство и бедность // Федеральная служба государственной статистики. URL: https://www.gks.ru/folder/13723 (дата обращения 14.08.2020).

16. Старшее поколение // Федеральная служба государственной статистики. URL: https://rosstat.gov.ru/folder/13877 (дата обращения 14.08.2020).

17. Ngamaba K.H., Panagioti M., Armitage C.J. Income inequality and subjective well-being: a systematic review and meta-analysis // Qual Life Res. - 2018. - № 27 (3). - P. 577-596.

18. Schneider S.M. Income inequality and subjective wellbeing: trends, challenges, and research directions // Journal of Happiness Studies. $-2016 . \quad-\quad$ № $17 . \quad-\quad$ P. 1719-1739. URL: https://www.researchgate.net/publication/281236051_Income_Inequality_and_Subjective_Wellbeing_Trend s_Challenges_and_Research_Directions (дата обращения 14.08.2020).

19. Diener E., Tay L. Subjective well-being and human welfare around the world as reflected in the Gallup World Poll // Int J Psychol. - 2015. - № 50 (2). - P. 135-149.

20. Комплексное наблюдение условий жизни населения - 2016 // Федеральная служба государственной статистики. URL: http://www.gks.ru/free_doc/new_site/KOUZ16/index.html (дата обращения 14.08.2020).

Поступила 23.08.2020 2. 
UDC 332.142:316.346.32-053.9

\title{
REGIONAL ASPECT OF POVERTY AMONG OLDER ADULTS IN RUSSIA
}

\author{
Elena A. Frolova 1 , \\ frolova_ea@mail.tsu.ru \\ Veronika A. Malanina², \\ milanskaya@mail.ru \\ Casati Fabio², \\ fabio.casati@gmail.com \\ Anna A. Shavlokhova ${ }^{2}$, \\ ollyvost@tpu.ru
}

\author{
${ }^{1}$ National Research Tomsk State University, \\ 36, Lenin avenue, Tomsk, 634050, Russia \\ ${ }^{2}$ National Research Tomsk Polytechnic University, \\ 30, Lenin avenue, Tomsk, 634050, Russia
}

Elena A. Frolova, Dr. Sc., professor, National Research Tomsk State University.

Veronika A. Malanina, Cand. Sc., associate professor, National Research Tomsk Polytechnic University.

Casati Fabio, PhD, leading researcher, Lifelong Wellbeing Lab, National Research Tomsk Polytechnic University.

Anna A. Shavlokhova, engineer, National Research Tomsk Polytechnic University.

In world economic science and politics, the fight against poverty and inequality continues to be relevant, despite decades of efforts to overcome them. For people of working age and below working age, efforts have traditionally been focused on ensuring access to education and jobs. Alleviating old-age poverty is less straightforward because of the lower marginal utility of education and declining opportunities for access to high-paying jobs. It is assumed that the well-being of the older generation is guaranteed either by the state or by the elderly themselves, who receive returns on investments made during their life course. The purpose of this study was to search for institutional and personal factors that act and form throughout the life course and determine the well-being of older adults. We tested such factors as education, work experience, number of household members, marital status, gender, area of residence (city vs rural) and region of residence. Methods: the method of descriptive statistics and correlation analysis on the samples of the Comprehensive Monitoring of Living Conditions (CMLC-2018) for people of retirement age in Russia. Additionally, to verify the results, we used the data from the Sample Survey of Population Income and Participation in Social Programs (VNDN-2017) and the European Social Survey (ESS-2018). Results. Correlations between indicators of socioeconomic status showed that only the number of household members in VNDN and ESS samples significantly and strongly positively correlates with income in old age. Unemployment has a negative correlation with income for city residents and women. Differences in absolute and relative poverty assessments for Federal districts vary from 1 to $240 \%$. Subjective poverty among households in Russia exceeds $50 \%$.

Key words: Older adults, poverty, subjective poverty, income, employment, households, Federal districts.

The study was supported by the Russian Science Foundation (project no. 19-18-00282). 


\section{REFERENCES}

1. Tseli OON v oblasti ustoychivogo razvitiya [United Nations sustainable development goals]. Available at: https://www.un.org/sustainabledevelopment/ru/sustainable-development-goals/ (accessed 14 August 2020).

2. Doklad o neravenstve v mire - 2018: osnovnye polozheniya [World Inequality Report 2018: key points]. Available at: https://wir2018.wid.world/files/download/wir2018-summary-russian.pdf (accessed 14 August 2020).

3. Sen A.K. Poor, relatively speaking. Oxford Economic Papers, 1983, vol. 35, no. 2, pp. 153-169.

4. Sen A.K. From income inequality to economic inequality. Southern Economic Journal, 1997, vol. 64, no. 2, pp. 383-401.

5. Early J.F. Reassessing the facts about inequality, poverty, and redistribution. Policy Analysis, 2018, no. 839. Washington, Cato Institute. Available at: https://www.cato.org/publications/policy-analysis/reassessingfacts-about-inequality-poverty-redistribution (accessed 14 August 2020).

6. Kapelyushnikov R.I. Ekonomicheskoe neravenstvo - vselenskoe zlo? [Economic inequality - universal evil?]. Moscow, Higher School of Economics publishing house, 2019. 28 p.

7. Mareeva S., Tikhonova N. Bednost i sotsialnye neravenstva v Rossii v obshchestvennom soznanii [Public Perceptions of Poverty and Social Inequality in Russia]. Mir Rossii, vol. 25, no. 2, pp. 37-67.

8. Is poverty measurable? World Economic Forum. 2019. Available at: https://www.weforum.org/agenda/ 2019/10/extreme-poverty-measurement-historian/ (accessed 14 August 2020).

9. The OECD approach to measure and monitor income poverty across countries. United nations economic commission for Europe conference of European statisticians. Available at: https://www.unece.org/fileadmin/DAM/stats/documents/ece/ces/ge.15/2013/WP_17_OECD_D_En.pdf (accessed 14 August 2020).

10. Kompleksnoe nablyudenie usloviy zhizni naseleniya -2018 [Complex observation of living conditions of the population 2018]. Federalnaya sluzhba gosudarstvennoy statistiki. Available at: https://www.gks.ru/ free_doc/new_site/KOUZ18/index.html (accessed 14 August 2020).

11. Vyborochnoe nablyudenie dokhodov naseleniya i uchastiya v sotsialnykh programmakh - 2017 [Selective observation of population incomes and participation in social programs 2017]. Federalnaya sluzhba gosudarstvennoy statistiki. Available at: https://www.gks.ru/free_doc/new_site/vndn-2017/index.html (accessed 14 August 2020).

12. European Social Survey. Available at: http://www.europeansocialsurvey.org/ (accessed 14 August 2020).

13. Zubarevich N. Chetyre Rossii i novaya politicheskaya realnost [Four Russias and a new political reality]. POLIT.RU. Available at: https://polit.ru/article/2016/01/17/four_russians/ (accessed 14 August 2020).

14. Velichina prozhitochnogo minimuma [The value of the subsistence minimum]. Federalnaya sluzhba gosudarstvennoy statistiki [Federal State Statistics Service]. Available at: https://rosstat.gov.ru/free_doc/ new_site/population/urov/vpm/proj-min.html (accessed 14 August 2020).

15. Neravenstvo i bednost [Inequality and Poverty]. Federalnaya sluzhba gosudarstvennoy statistiki [Federal State Statistics Service]. Available at: https://www.gks.ru/folder/13723 (accessed 14 August 2020).

16. Starshee pokolenie [Older generation]. Federalnaya sluzhba gosudarstvennoy statistiki [Federal State Statistics Service]. Available at: https://rosstat.gov.ru/folder/13877 (accessed 14 August 2020).

17. Ngamaba K.H., Panagioti M., Armitage C.J. Income inequality and subjective well-being: a systematic review and meta-analysis. Qual Life Res., 2018, no. 27 (3), pp. 577-596.

18. Schneider S.M. Income inequality and subjective wellbeing: trends, challenges, and research directions. Journal of Happiness Studies, 2016, no. 17, pp. 1719-1739. Available at: https://www.researchgate.net/publication/281236051_Income_Inequality_and_Subjective_Wellbeing_Trends_Challenges_and_Research_Directions (accessed 14 August 2020).

19. Diener E., Tay L. Subjective well-being and human welfare around the world as reflected in the Gallup World Poll. Int J Psychol., 2015, no. 50 (2), pp. 135-149.

20. Kompleksnoe nablyudenie usloviy zhizni naseleniya - 2016 [Comprehensive monitoring of the living conditions of the population 2016]. Federalnaya sluzhba gosudarstvennoy statistiki [Federal State Statistics Service]. Available at: http://www.gks.ru/free_doc/new_site/KOUZ16/index.html (accessed 14 August 2020).

Received: 23 August 2020. 